\title{
MPRA
}

Munich Personal RePEc Archive

\section{Asset Market Liquidity Risk Management: A Generalized Theoretical Modeling Approach for Trading and} Fund Management Portfolios

\author{
Al Janabi, Mazin A. M. \\ UAE University \\ 20 May 2009 \\ Online at https://mpra.ub.uni-muenchen.de/19498/ \\ MPRA Paper No. 19498, posted 22 Dec 2009 06:14 UTC
}




\title{
Asset Market Liquidity Risk Management: A Generalized Theoretical Modeling Approach for Trading and Fund Management Portfolios
}

\author{
Contacting Author Details:
}

Mazin A. M. Al Janabi, Ph.D.

Associate Professor of Finance and Banking

Department of Economics and Finance

College of Business and Economics

United Arab Emirates University

P.O. Box 17555, Al-Ain, United Arab Emirates.

Tel: +(971) 3-7133231, Fax: +(971) 3-7624384

E-mail: m.aljanabi@uaeu.ac.ae \& mazinaljanabi@gmail.com

\section{Draft Version Accepted for Presentation: Quantitative Methods in Finance Conference (QMF) 2009, Sydney, Australia 16-19-December, 2009}

20-May, 2009

\begin{abstract}
Biographical notes: Mazin A. M. Al Janabi is associate professor of finance and banking and has several years of real-world experience in financial markets and banking sectors. He has held a number of senior positions, such as Head of Trading of Financial Derivative Products, Head of Trading Risk Management, Director of Asset and Liability Management and Director of Global Market Risk Management. He has written extensively, in leading scholarly journals, on finance \& banking and contemporary topics in trading, market and credit risk management. His research and consulting activities address practitioner and regulatory issues in finance \& banking, financial risk management and derivative securities.
\end{abstract}

Copyright (C) Mazin A. M. Al Janabi, 2009-2010 


\title{
Asset Market Liquidity Risk Management: A Generalized Theoretical Modeling Approach for Trading and Fund Management Portfolios
}

\begin{abstract}
:
Asset market liquidity risk is a significant and perplexing subject and though the term market liquidity risk is used quite chronically in academic literature it lacks an unambiguous definition, let alone understanding of the proposed risk measures. To this end, this paper presents a review of contemporary thoughts and attempts vis-à-vis asset market/liquidity risk management. Furthermore, this research focuses on the theoretical aspects of asset liquidity risk and presents critically two reciprocal approaches to measuring market liquidity risk for individual trading securities, and discusses the problems that arise in attempting to quantify asset market liquidity risk at a portfolio level. This paper extends research literature related to the assessment of asset market/liquidity risk by providing a generalized theoretical modeling underpinning that handle, from the same perspective, market and liquidity risks jointly and integrate both risks into a portfolio setting without a commensurate increase of statistical postulations. As such, we argue that market and liquidity risk components are correlated in most cases and can be integrated into one single market/liquidity framework that consists of two interrelated sub-components. The first component is attributed to the impact of adverse price movements, while the second component focuses on the risk of variation in transactions costs due to bid-ask spreads and it attempts to measure the likelihood that it will cost more than expected to liquidate the asset position. We thereafter propose a concrete theoretical foundation and a new modeling framework that attempts to tackle the issue of market/liquidity risk at a portfolio level by combining two asset market/liquidity risk models. The first model is a re-engineered and robust liquidity horizon multiplier that can aid in producing realistic asset market liquidity losses during the unwinding period. The essence of the model is based on the concept of Liquidity-Adjusted Value-at-Risk (L$\mathrm{VaR}$ ) framework, and particularly from the perspective of trading portfolios that have both long and short trading positions. Conversely, the second model is related to the transactions cost of liquidation due to bid-ask spreads and includes an improved technique that tackles the issue of bidask spread volatility. As such, the model comprises a new approach to contemplating the impact of time-varying volatility of the bid-ask spread and its upshot on the overall asset market/liquidity risk.
\end{abstract}

JEL Classifications: C10, C13, G20, and G28

Keywords: Economic Capital; Emerging Markets; Financial Engineering; Financial Risk Management; Financial Markets; Liquidity Risk; Portfolio Management; Liquidity Adjusted Value at Risk. 


\section{INTRODUCTION AND OVERVIEW}

Whilst a great deal has been written on the topic of credit and market (or price) risk, relatively little appears on the important issue of liquidity risk for large security positions in illiquid markets. Asset liquidity risk is a large and confusing subject and indeed, the lack of liquidity in trading portfolios is perhaps one of the prevalent threats facing today's capital markets and has played a key role in major crises and losses during the last two decades.

Market liquidity refers to the ability to undertake financial securities transactions in such a way as to adjust trading portfolios and risk exposure profiles without significantly disturbing prevailing market condition and underlying prices. Market liquidity risk is a function of the depth ${ }^{1}$ of the markets and their continuity and it is influenced by trading strategies and by the type of hedge chosen, if the strategy involves hedging of exposure. Moreover, it is also a function of transaction size, product type, current market sentiment and local trading patterns.

Market liquidity depends fundamentally on the existence of enough number of counterparties and their readiness to trade. The latter depends on investors' expectations vis-à-vis price level developments and also their risk aversion, as well as the available information at a given time. Underprivileged liquidity conditions thus indicates a relatively small number and size of daily transactions and gives an indication of the size of a portfolio trading position that the market can absorb at a given level. An entirely liquid financial market would therefore pledge a single bid/ask price at all times and regardless of the asset quantities being traded. In fact, financial markets, even those viewed the most liquid conform less than perfectly to this extreme pattern. As a result asset liquidity risk is the risk of not being competent to promptly liquidate or hedge a trading position at existing market prices. Indeed, this market liquidity risk is unlike balance-sheet liquidity risk, which arises from the incapability to raise liquid funds by offloading assets or liabilities from the balance-sheet's books. The former asset liquidity risk is the focus of this paper.

As it happens, changes in market operational conditions as well as the magnitude and nature of financial risk have demanded the writing down and structuring of Basel II Capital Accord, ${ }^{2}$ basically a revised and enlarged framework of Basel I. This amendment leaves the treatment of market risk largely unaltered from Basel I requirements and instead focuses almost exclusively upon the formerly mistreated areas of credit and operational risks. Indeed, a key

\footnotetext{
${ }^{1}$ Depth is defined as the volume of possible trades without affecting prevailing market prices on order books.

${ }^{2}$ The Basel Capital Accord sets down the agreement among the G-10 central banks to apply common minimum capital standards to their banking institutions. The standards largely address the main risks incurred by banks such as credit, market and operational. Currently, the Basel II accord is embraced by other countries apart from the G-10 countries.
} 
advancement of the Basel II Capital Accord was the introduction of Value at Risk (VaR) as an internal risk measure to consolidate an institution's market risk into a single number expressed usually in monetary terms. Whereas VaR is not a demanding quantity to evaluate in principle, assessing its key parameters and determining both their robustness and validity are non-trivial.

Effectively, a large number of research articles are nowadays concerned in the examination of the intricacy of credit and operational risks, while market risk has received lesser attention and as a result market risk research papers have lessened notably in number. Definitely, the VaR concept, however, has by no means been thoroughly looked into. One such ignored feature is asset liquidity risk which, because of its trend to compound other risks, is complex to detach and appraise effectively. In all but the most simple of situations, thorough asset market/liquidity risk metrics do not exist and traditional VaR models typically disregard asset liquidity risk entirely.

The existing attempts on the measurement of liquidity risk are poorly defined and whether we agree or disagree upon it $\mathrm{VaR}$ can at least be viewed as a starting point in contemplating the assessment of market risk. Unfortunately, there is no such standard point of departure for market liquidity risk measurement. Nonetheless, where liquidity risk is assessed at all, it is typically through deviations on two types of yardsticks. The first attempts to measure transactions cost risk and is based on the concept of bid-ask spreads, while the second endeavors to capture the risk of bearing down prevailing market prices by selling large quantities, and is anchored in trade volume or outstanding positions. In most situations, however, market liquidity risk is measured in terms of a bid/ask spread and represents the costs to unwind the trading position; or alternatively it is assessed by adding an off-the-cuff liquidity risk multiplier ${ }^{3}$ to the overall market risk exposure, usually measured by a traditional VaR models. Therefore, traditional adjustments to VaR models are done on an ad hoc basis and liquidity risk is factored loosely into VaR measures by assuring that the liquidation horizon is at least greater than an orderly unwinding period. By and large, the same horizon is applied to all asset classes, even though some trading assets may be more liquid than others.

Despite some research into liquidity risk measurement, the financial services industry still finds it difficulty to quantify and predict measurable attributes of market liquidity risk. In fact, most financial institutions have committed or are preparing to commit significant resources to managing liquidity risk. But there are no clear standards regarding the definition of the problem

\footnotetext{
${ }^{3}$ A multiplier that is incorrectly used quite frequently by researchers and practitioners is the square root of time since it overstates the overall market risk.
} 
these entities' efforts are meant to solve, let alone the risk measures themselves. In the absence of accepted industry standards, risk professionals are faced with the challenge of defining an organization-specific internal approach that addresses market liquidity risk not only for a single trading security but rather on an aggregate portfolio level. This is where this research comes in, as we strive to clarify the essence of asset market/liquidity risk, provide clear definition of the topic and suggest methods for its mutual assessment at a portfolio level.

In this work, we argue that market/liquidity risk associated with the uncertainty of adverse price impact and the widening of the bid-ask spread, particularly for thinly traded or emerging market securities under adverse market conditions, are important parts of the overall asset market/ liquidity risk and are therefore important components to model mutually. Next we develop a clearcut market/liquidity risk methodology that can be easily and flawlessly incorporated into standard VaR models and can be applied at a trading/investment portfolio level. Furthermore, we explain that ignoring any of the two components of liquidity effect can produce underestimates of market risk, particularly in emerging markets. Accordingly, we verify that the Basel II Capital Accord inadvertently is already monitoring liquidity risk and that by not modeling it unequivocally as part of the overall market/liquidity uncertainty and therefore capitalizing against it, financial entities will be encountering despicably many violations of their capital requirements, particularly if their trading portfolios are clustered in emerging markets.

To this end, this paper is an effort to describe and evaluate contemporary attempts in addressing market liquidity risk and to propose a concrete generalized theoretical asset market/liquidity modeling approach that can jointly tackle the measurement of these two risks for trading and asset management portfolios. It is anticipated in a second phase to apply the theoretical modeling framework developed herein to an emerging financial market, subject to obtaining a reliable and robust source of stratified market dataset. We aspire in the succeeding part II to originate an empirical research paper by applying the theoretical modeling approach developed in this work to a particular case of an emerging market trading portfolio. Our aim would be to test the dataset empirically and to analyze the influence of both adverse price impact and transactions cost on the overall market/liquidity risk profiles by enforcing meaningful financial and operational constraints.

The rest of the paper proceeds as follows: Section 2 presents a review of current thinking and practices regarding liquidity risk measurement and thereafter highlights the main contributions of this research. Section 3 discusses the salient features of asset market/liquidity risk and derives

\section{Copyright (C) Mazin A. M. Al Janabi, 2009-2010}


the necessary quantitative infrastructure of two interrelated models. First, we present our conceptual framework for understanding market/liquidity risk, and their interaction and then show that Liquidity-Adjusted Value at Risk (L-VaR), as a measure of adverse price impact market/liquidity risk, can be derived for a single-asset portfolio assuming uniform liquidation over the holding period. We then broaden the analysis from one security to an entire portfolio and derive a general model that incorporates the effects of holding multiple long and short illiquid assets on market and liquidity risk management by simply scaling the multi-assets' L-VaR matrix. The discussion then turns to incorporate the impact of transactions costs and to develop a model that considers the time-varying volatility of the bid-ask spread. Finally, we integrate the various components of the overall market/liquidity value uncertainty and techniques for their measurement, with emphasis on the total market/liquidity risk components and our modeling approach. Section 4 remarks on conclusions with a brief summary and recommendation for future research on the possible empirical applications of the theoretical modeling approach contained in this part I research paper.

\section{LITERATURE REVIEW AND RATIONALE OF PRESENT WORK}

A widespread number of contemporary literatures dealing with the microstructure of financial markets have been dedicated to categorize the determinants of market and liquidity risks and to model the nexus between both risks. Likewise, frequent studies on financial crises show that the shortage of liquidity is an element that is always present in times of major financial crises. Nevertheless, liquidity risk, a major component of market risk that is challenging to grasp, is still not sufficiently accounted for in modern risk assessment and management methods.

Indeed, on one side methods for measuring market risk have been well developed and standardized in the academic as well as the banking world. Liquidity trading risk, on the other hand, has received less attention from researchers, perhaps because it is less significant in developed countries where most of the market risk methodologies were originated. In all but the most simple of circumstances, comprehensive metrics of liquidity trading risk management do not exist explicitly within modern portfolio theory.

In effect, the conventional $\mathrm{VaR}$ approach to computing market (or trading) risk of a portfolio does not explicitly consider liquidity risk. Typical VaR models are based on modern portfolio management theory and assess the worst change in mark-to-market portfolio value over a given time horizon but do not account for the actual trading risk of liquidation. In general,

\section{Copyright (C) Mazin A. M. Al Janabi, 2009-2010}


customary fine-tunings are made on an ad hoc basis. At most, the holding period (or liquidation horizon) over which the VaR number is calculated is adjusted to ensure the inclusion of liquidity risk. As a result, liquidity trading risk can be imprecisely factored into VaR assessments by assuring that the liquidation horizon is as a minimum larger than an orderly liquidation interval. Moreover, the same liquidation horizon is employed to all trading asset classes, albeit some assets may be more liquid than others.

Effectively, not only does this technique not differentiate between the various kinds of asset market/liquidity risks, but it employs the square-root of time multiplier, in which it is assumed that no autocorrelation exists between the rates of return on asset from one measurement period to another. The presumption of a lack of autocorrelation permits for simple addition of individual variances to produce the overall variance of the holding period. This postulation has been disputed over the past two decades by several authors [see for example, Danielsson and Zigrand (2006)]. In addition, Al Janabi (2008) recently reveals that the square-root of time rule leads to a systematic overestimation of market risk. The author concludes that despite the widespread application and implementation of the square-root of time multiplier in Basel II regulatory accord, it nevertheless fails short to address the aim of Basel II accord. It is clear that a comprehensive investigation into the nature of asset market/liquidity risk and its effect on distinct portfolios of both long and short illiquid assets is necessary.

Without a doubt, neglecting liquidity risk can lead to an underestimation of the overall market risk and misapplication of capital cushion for the safety and soundness of financial institutions. In emerging financial markets, which are relatively well thought-out as illiquid, ignoring the liquidity risk can result in significant underestimation of the VaR estimate, and especially under severe market conditions (Al Janabi, 2008). As a result, the increase tradability of assets in emerging markets necessitates a reexamination of current market and liquidity risk management techniques; and specifically for trading or investment funds portfolios—of either merely long positions or a combination of long/short trading positions - and within short horizons of re-balancing and reporting focuses.

As such, the combination of the latest swift expansion of emerging markets' trading activities and the persistent turbulence in those markets has impelled liquidity trading risk to the vanguard of market risk management research and development. To this end, within the VaR framework, Jarrow and Subramanian (1997) provide a market impact model of liquidity by considering the optimal liquidation of an investment portfolio over a fixed horizon. They derive

\section{Copyright $($ C Mazin A. M. Al Janabi, 2009-2010}


the optimal execution strategy by determining the sales schedule that will maximize the expected total sales values, assuming that the period until liquidation is given as an exogenous factor. The correction to the lognormal VaR they derive depends on the mean and standard deviation of both: an execution lag function and of a liquidation discount. Although the model is simple and intuitively appealing, it suffers from practical difficulties for its implementation. It requires the estimation of additional parameters such as the mean and the standard deviation of the discount factor and the period of execution-for which data are not readily available, none of which may be easy to estimate and may require subjective estimates such as a trader's intuition.

Bangia et al. (1999) approach the liquidity risk from another angle and provide a model of $\mathrm{VaR}$ adjusted for what they call exogenous liquidity-defined as common to all market players and unaffected by the actions of any one participant. It comprises such execution costs as order processing costs and adverse selection costs resulting in a given bid-ask spread faced by investors in the market. On the contrary, endogenous liquidity is specific to one's position in the market and depends on one's actions and varies across market participants. It is mainly driven by the size of the position: the larger the size, the greater the endogenous illiquidity. They propose splitting the uncertainty in market value of an asset into two parts: a pure market risk component arises from asset returns and uncertainty due to liquidity risk. Their model consists of measuring exogenous liquidity risk, computed using the distribution of observed bid-ask spreads and then integrating it into a standard $\mathrm{VaR}$ framework. Indeed, their argument is based on treating liquidity risk and market risk jointly and thus they make the assumption that in adverse market environments extreme events in both returns and spreads arise concurrently. They argue that while the correlation between asset mid-price movements and bid-ask spreads is not perfect it is strong enough during severe market conditions to persuade the handling of extreme movements in market and liquidity risk simultaneously. Accordingly, they incorporate both a $99^{\text {th }}$ percentile movement in the underlying and a $99^{\text {th }}$ percentile movement in the bid-ask spread and estimate for example that, in May 1997, asset liquidity risk accounted for over $17 \%$ of the market risk of a long position on USD/Thai Baht and for only $1.5 \%$ for liquid positions on USD/Yen.

Using a similar methodology, Le Saout (2002) applies the model developed by Bangia et al. (1999) to the French stock market (CAC-40) and states that neither exogenous liquidity risk (which accounts for about half of total market risk) nor endogenous liquidity risk (also a potentially significant component of market risk) should be overlooked by financial entities subject to market risk. In an attempt to consider the effect of liquidating large positions, Le Saout (2002)

\section{Copyright (C) Mazin A. M. Al Janabi, 2009-2010}


incorporates the weighted average spread into the L-VaR measure. The author's results indicate that exogenous liquidity risk, for illiquid stocks, can represent more than a half of total market risk (up to $52 \%$ for certain securities). Furthermore, the author extends the model to incorporate endogenous liquidity risk and shows that it represents an important component of the overall liquidity risk. In a parallel study, Roy (2004) relates the model provided by Bangia et al. (1999) to the Indian debt market and finds that liquidity risk accounts for some $16 \%$ of the total risk on little traded securities. First, the author presents a comprehensive survey of L-VaR models and then adopts a modified version of the exogenous liquidity approach suggested by Bangia et al. (1999). In that paper, a measure of $\mathrm{L}-\mathrm{VaR}$, based on bid-ask spread, is presented and the liquidity risk found to be an important component of the aggregate risk absorbed by financial institutions. The shortcoming of this methodology, however, is that it necessitates large samples of daily or even intraday trading data, which are not consistently obtainable.

In a relatively recent study, Angelidis and Benos (2006) loosen the conventional, yet idealistic, postulation of perfect and frictionless financial markets (that is, traders can either buy or sell any amount of securities without triggering major price changes). To this end, Angelidis and Benos (2006) expand the earlier work of Madhavan et al. (1997) (who debated that traded volume can explicate security price movements) and exploit an L-VaR model based on bid-ask spread components, following the earlier work of Bangia et al. (1999). The authors argue that under this structure, asset liquidity risk is decomposed into its endogenous and exogenous components, thereby allowing an estimation of the liquidation risk of a specific trading position. The authors then apply L-VaR measures to the Athens Stock Exchange by incorporating bid-ask variation and the price effect of position liquidation. Their study focuses on the use of high frequency transaction level data of stocks besides sorting out each stock according to their average transaction prices and capitalization. Furthermore, the results indicate that adverse selection increases with trade size while the cost component of the bid-ask spread decreases. Based on these findings, endogenous and exogenous liquidity risks are linked to spread components. For highpriced, high-capitalization stocks, it is found that a VaR correction for illiquidity is not necessary since liquidity risk represents only $3.40 \%$ of total market risk. On the other hand, for low capitalization stocks, the percentage of risk due to illiquidity reaches as much as $11 \%$ of total market risk and hence it should not be neglected in the overall assessment of L-VaR. As with much other research on L-VaR, this pertinent and thorough work does not attempt to address portfolio liquidity risk, the foremost motive of this paper.

\section{Copyright (C) Mazin A. M. Al Janabi, 2009-2010}


Almgren and Chriss (1999) present a concrete framework for deriving the optimal execution strategy using a mean-variance approach, and show a specific calculation method. Their approach has a high potential for practical application. They assume that price changes are caused by three factors: drift, volatility, and market impact. Their analysis leads to general insights into optimal portfolio trading, relating risk aversion to optimal trading strategy, and to several practical implications including the definition of L-VaR. Unlike Almgren and Chriss (1999), Hisata and Yamai (2000) turn the sales period into an endogenous variable and propose a practical framework for the quantification of $\mathrm{L}-\mathrm{VaR}$ which incorporated the market liquidity of financial products. Their model incorporates the mechanism of the market impact caused by the investor's own dealings through adjusting $\mathrm{VaR}$ according to the level of market liquidity and the scale of the investor's position. In addition, Hisata and Yamai (2000) propose a closed-form solution for calculating L-VaR as well as a method of estimating portfolio L-VaR.

On another front, Berkowitz (2000) argues that unless the likely loss arising from liquidity risk is quantified, the models of VaR would lack the power to explicate the embedded risk. In practice, operational definitions vary from volume-related measures to bid-ask spreads and to the elasticity of demand. The author asserts that elasticity based measures are of most relevance since they incorporate the impact of the seller actions on prices. Moreover, under certain conditions the additional variance arising from seller impact can easily be quantified given observations on portfolio prices and net flows; and that it is possible to estimate the entire distribution of portfolio risk through standard numerical methods.

Shamroukh (2000) contends that scaling the holding period to account for orderly liquidation can only be justified if we allow the portfolio to be liquidated throughout the holding period. The author extends the RiskMetrics ${ }^{T M}$ (1994) approach by explicitly modeling the liquidation of the portfolio over time and by showing that L-VaR can be easily obtained by an appropriate scaling of the variance-covariance matrix. Furthermore, market liquidity risk can be modeled by expressing the liquidation price as a function of trade sizes, thus imposing a penalty on instantaneous unwinding of large position. Following this approach, L-VaR can be viewed as a solution to a minimization problem arising from the trade-off between higher variance associated with slow liquidation and higher endogenous liquidity risk associated with fast liquidation. As a result, the holding period is an output of this model-that is the solution to the minimization problem. In another relevant study, Dowd et al. (2004) tackle the problem of estimating VaR for long-term horizon. In their paper they offer a different; however a rather straightforward, approach

\section{Copyright (C) Mazin A. M. Al Janabi, 2009-2010}


that avoids the inherited problems associated with the square-root of time rule, as well as those associated with attempting to extrapolate day-to-day volatility forecasts over long horizons.

Lately, in his research paper, Al Janabi (2008) establishes a practical framework for the measurement, management and control of trading risk. The effects of illiquid assets, that are dominant characteristics of emerging markets, are also incorporated in the risk models. This literature provides real-world risk management techniques and strategies (drawn from a practitioner viewpoint) that can be applied to trading portfolios in emerging markets. The intent is to propose a simple approach for including of liquidation trading risk in standard VaR analysis and to capture the liquidity risk arising due to illiquid trading positions by obtaining a L-VaR estimate. The key methodological contribution is a different and less conservative liquidity scaling factor than the conventional root-time multiplier. The proposed add-on is a function of a predetermined liquidity threshold defined as the maximum position which can be unwound without disturbing market prices during one trading day. In addition, the re-engineered model is quite simple to implement even by very large financial institutions with multiple assets and risk factors.

Despite the increasing importance of trading risk management, published research in this specific risk management area is slow to emerge and specifically from the perspective of asset market liquidity risk. In particular, the main endeavor of this paper is to fill a gap in the risk management literature (especially from the perspectives of emerging and illiquid markets) and to bridge the disparity between the academic and professional finance communities.

As indicated above, asset prices are exposed to a variety of volatile market prices that can be and have been examined in a portfolio context. However, despite the rising interest in emerging markets, earlier research does not provide any broad methods for handling trading risk under illiquid and adverse market settings and particularly within emerging markets trading portfolios. As such, the intent of this paper is to present two techniques that aim to assess the risks incurred in the event of a deterioration in asset market liquidity and to probe to what extent these techniques may add to improving the overall market risk control in financial institutions and also to aid the pertinent authorities to improve their appraisals of financial stability.

Considering the recent interest in market liquidity risk and the variability of the market risk factors of different emerging markets, the overall aim of this paper is to explore the impact of both adverse price and transactions cost liquidity measures in the context of trading portfolios (of either merely long positions or a combination of long/short trading positions) and under the notion of

\section{Copyright (C) Mazin A. M. Al Janabi, 2009-2010}


different correlation factors and liquidity horizons. In particular, this paper develops L-VaR and bid-ask spread risk measures with the aid of different liquidation horizons and under a predetermined confidence level. In contrast to all existing published literature pertaining to the application of L-VaR method to emerging markets, this paper proposes a new model for assessing a closed-form parametric L-VaR with explicit treatment of liquidity trading risk.

The principle adjustments that we present here consists essentially in adjusting traditional $\mathrm{VaR}$ method to take into consideration the liquidation of assets during the unwinding period along with incorporating the impact of the time-varying broadening of the bid-ask spread in times of stress conditions. As such, the main contribution of this work is to extend VaR calculation to allow for a steady liquidation of the portfolio over the holding period and by showing that liquidity risk can be straightforwardly and intuitively integrated into the proposed L-VaR framework. Rather than modeling liquidity trading risk as such, the central focus of this work is to devise a wideranging and adaptable framework for handling asset market/liquidity risk. The key methodological contribution is a different and more realistic liquidity scaling factor than the conventional root-time multiplier. The proposed add-on is a function of a predetermined liquidity threshold defined as the maximum position which can be unwound without disturbing market prices during one trading day. In addition, the re-engineered model is quite simple to implement even by very large financial institutions with multiple assets and risk factors. In this paper, we attempt to integrate and estimate the impact of liquidity trading risk into VaR models by explicitly incorporating the impact of both the time-volatility dimension of adverse asset prices and the dynamic movements in the bid-ask spread on market liquidity risk.

\section{MODELING UNCERTAINTY IN ASSET MARKET/LIQUIDITY RISK}

Asset market/liquidity risk in trading portfolios is the risk that the liquidation value of trading assets may differ significantly from their current mark-to-market values and hence it is a function of the size of the trading positions (i.e. adverse price impact risk) and the price impact of trades (i.e. transactions cost liquidity risk). The first component arises when the trader is unable to quickly sell a security at a fair price and this usually happens when few people normally trade the given security or it could happen if the general market is in crisis and very few people are interested in buying more securities. In such a situation, the trader is assumed to be taking an extreme course of action by closing out the trading positions at the mid-price and refusing to give any price discount. The other extreme is to assume that the trader will sell out immediately by 
giving a discount that brings the price down to the bid price. This discount is an additional loss and crop up with the second component (that is, the price impact of trades) and is characterized by an abrupt broadening of the bid-ask spread, or even the complete vanishing of buy/sell flows and the incapability to trade. This widening in the bid-ask spread can often lead to an escalation in shortterm volatility as well as the slump of financial markets as it contains the seeds of serious systemic turmoil. As a result, we can view these two possible loss mechanisms components as two extreme manifestations of the same problem. In one extreme, the trader slowly sells at the current fair price, but risks suffering additional losses. In the other extreme, the trader sells immediately at an unusually low price (in case he holds long position) or buys at high price in case he had short sold assets.

It is hence important to recognize the asset liquidity risk and its close relationship with market risk for trading position because it can add significant losses to the overall market risk exposure. Furthermore, if liquidity risk is not included in the risk measurements, it can give incentive to traders to buy illiquid securities since illiquid securities offer a higher expected return to compensate for their higher liquidity risk.

Since market and liquidity risks are interrelated and can simultaneously impact each other, it is then possible to define with reasonable accuracy that the overall market and liquidity risk of a trading position is the sum of two interrelated subcomponents, namely: 1) adverse price impact market liquidity risk component, and 2) transactions cost market liquidity risk component. In the following sections we define each of these components and then provide a rational explanation for the aggregation of both components for the sake of providing a generalized measure of both market and liquidity risks.

\subsection{Capturing Asset Return Uncertainty Using Parametric VaR Approach :}

One of the most significant advances in the past two decades in the field of measuring and managing financial risks is the development and the ever-growing use of VaR methodology. VaR has become a useful tool for monitoring risk, and its use is being encouraged by the Bank for International Settlements (BIS) and Basel II committee on banking supervision. As a result, VaR has turned into the standard measure that financial analysts use to quantify financial risks including trading risk. VaR represents the potential loss in the market-value of a portfolio of assets with a given probability over a certain time horizon. The main advantage of VaR over other risk measures is that it is theoretically simple and can be used to summarize the risk of an individual asset 
position or the risk of large portfolios of trading assets. Thus, VaR reduces the risk associated with any portfolio of trading assets to just one number-the expected loss associated with a given probability over a defined holding period.

To calculate VaR using the parametric method, the volatility of each risk factor is extracted from a pre-defined historical observation period. The potential effect of each component of the portfolio on the overall portfolio value is then worked out. These effects are then aggregated across the whole portfolio using the correlations between the risk factors (which are, again, extracted from the historical observation period) to give the overall $\mathrm{VaR}$ value of the portfolio with a given confidence level. A simplified calculation process of the estimation of VaR risk factors (using parametric method) for a single and multiple assets' positions is illustrated [Al Janabi, (2005) and (2007)] as follows:

We begin by defining one-day asset return at time $t, R_{i, t}$ to be the log difference of mid-prices:

$R_{i, t}=\ln \left(P_{i, t}\right)-\ln \left(P_{i, t-1}\right)=\ln \left[\left(P_{i, t}\right) /\left(P_{i, t-1}\right)\right]$

Where $R_{i, t}$ is the daily return of asset $i, \ln$ is the natural logarithm; $P_{i, t}$ is the current price level of asset $i$, and $P_{i, t-1}$ is the previous day asset price. Furthermore, from elementary statistics it is well known that for a Gaussian distribution, $68 \%$ of the observations will lie within $1 \sigma$ (standard deviation) from the expected value, $95 \%$ within $2 \sigma$ and $99 \%$ within $3 \sigma$ from the expected value. Accordingly, by taking a one-day horizon over which the change in asset value is considered, and assuming that one-day returns are Gaussian, the worst VaR of a single asset in monetary terms is:

VaR $_{i}=\alpha *$ Mark-to-Market Value of Asset ${ }_{i} * \sigma_{i}$

where $\alpha$ is the confidence level (or in other words, the standard normal variant at confidence level $\alpha)$ and $\sigma_{i}$ is the standard deviation (volatility) of the asset that constitutes the single position. The Mark-to-Market Value of Asset ${ }_{i}$ (henceforth, $A_{i}$ ) indicates the amount of trading position in asset $i$. Without a loss of generality, we assume that the expected value of daily returns $E\left[R_{i, t}\right]$ is zero. Though equation (2) includes some simplifying assumptions, yet it is routinely used by researchers and practitioners in the financial markets for the estimation of $\mathrm{VaR}$ for a single trading position.

Trading risk in the presence of multiple risk factors is determined by the combined effect of individual risks. The extent of the total risk is determined not only by the magnitudes of the

\section{Copyright (C) Mazin A. M. Al Janabi, 2009-2010}


individual risks but also by their correlations. Portfolio effects are crucial in risk management not only for large diversified portfolios but also for individual assets that depends on several risk factors. For multiple assets or a portfolio of assets, VaR is a function of each individual asset's risk and the correlation factor between the returns on the individual assets, and as follows:

$\operatorname{VaR}_{P}=\sqrt{|\operatorname{VaR}|^{T}|\rho||\operatorname{VaR}|}$

This formula is a general one for the calculation of $V a R_{P}$ for any portfolio regardless of the number of assets and it simply contains the VaRs for the constituent assets. It should be noted that this formula is presented in terms of matrix-algebra - a useful form to avoid mathematical complexity, as more and more securities are added. This approach can simplify the programming process and permits easy incorporation of short-sales positions in market risk management process. This means, in order to calculate the $\mathrm{VaR}$ (of a portfolio of any number of assets), one needs first to create a vector $|\operatorname{VaR}|$ of individual VaR asset positions-explicitly $n$ rows and one column $(n * 1)$ vector-a transpose vector $|\operatorname{VaR}|^{T}$ of individual VaR asset positions-an $\left(1 *_{n}\right)$ vector, and hence the superscript " $T$ " indicates transpose of the vector-and finally a matrix $|\rho|$ of all correlation factors between all assets $(\rho)$-an $(n * n)$ matrix. Consequently, as one multiplies the three matrices and then takes the square root of the result, one ends up with the $\operatorname{VaR}_{P}$ of any portfolio with any $n$-number of assets. It should be noted that when reporting individual VaRs these figures are always taken as positive, even though they represent a loss (which conventionally has a negative sign). In assessing the portfolio $\operatorname{VaR}_{P}$ the sign of each trading asset " $A_{i}$ " must be incorporated into the $|\operatorname{VaR}|^{T}$ and $|V a R|$ vectors. That is, if the asset position is held long (i.e. you own it), then the $A_{i}>0$, but if the asset has been sold short, then $A_{i}<0$.

Worst-case $\operatorname{VaR}_{P}$ (or undiversified $\operatorname{VaR}_{P}$ ) can be deduced as a special case of equation (3) under the assumption that asset returns are perfectly positively correlated $(\rho=+1)$ and that there are positive amounts of each asset. This indeed will give the worst-case scenario, since there are no benefits from diversification by holding multiple assets. Thus, the maximum value that the $\operatorname{VaR}_{P}$ can take is given by setting $\rho=+1$ in equation (3), which gives:

$$
\text { Worst-case } \operatorname{VaR}_{P}=V a R_{1}+V a R_{2}+\ldots . .+\operatorname{Va} R_{n}=\sum_{i=1}^{n} \operatorname{VaR}
$$


Hence, in a worst-case scenario the $\operatorname{VaR}_{P}$ is simply the sum of the individual VaRs. In the realworld practices it is unlikely that the correlation between the returns of the constituent assets is $\rho$ $=+1$. However, under severe or crisis periods, it is often the case that correlation factors increase, and the worst-case $\operatorname{VaR}_{P}$ provides a high figure that may be representative of these crisis periods. Indeed, in real-world risk management practices, risk managers usually look at both the diversified $\operatorname{VaR}_{P}$ [equation (3)] and the worst-case $\operatorname{VaR}_{P}$ [equation (4)]. This gives the risk managers a feel for what would happen if historical correlations did not stay the same but rather increased due to a crisis period. Moreover, it is worth noting that if $\rho=+1$ and one or more of the constituent trading assets is a short position (that is, $A_{i}<0$ ), then there will be some risk offset and hence the worst-case scenario $\operatorname{VaR}_{P}$ equation (4) cannot be hold as a representative of the maximum loss of the trading portfolio.

\subsection{Modeling Adverse Price Impact Market Liquidity Risk:}

Trading asset liquidity is a key risk factor, which until lately, has not been appropriately dealt with by risk models. Illiquid trading positions can add considerably to losses and can give negative signals to traders due to the higher expected returns they entail. The concept of liquidity trading risk is immensely important for using $\mathrm{VaR}$ accurately and recent upheavals in financial markets confirm the need for laborious treatment and assimilation of liquidity trading risk into VaR models.

In effect, traditional $\mathrm{VaR}$ models presume that the portfolio is stationary over the liquidation horizon and that market prices represent attainable transaction prices. This marking-tomarket approach is adequate to quantify and control risk for an ongoing trading portfolio but may be more questionable if $\mathrm{VaR}$ is supposed to represent the worst loss over the unwinding period. As such, the question that may arise is how to adapt VaR to cope with asset liquidity consideration.

Asset market/liquidity risk arises when a forced liquidation of trading assets create unfavorable price movements. Thus liquidity considerations should be viewed in the context of both the asset and the liabilities of the financial entity. The simplest way to account for asset liquidity trading risk is to extend the holding period of illiquid positions to reflect a suitable liquidation period. An adjustment can be made by adding a multiplier to the VaR measure of each trading asset type, which at the end depends on the liquidity of each individual security. Nonetheless, the weakness of this method is that it allows for subjective estimation of the

\section{Copyright (C) Mazin A. M. Al Janabi, 2009-2010}


liquidation period. Furthermore, the typical assumption of a one-day horizon (or any inflexible time horizon) within VaR framework, neglects any calculation of trading risk related to liquidity effect (that is, when and whether a trading position can be sold out and at what price). A broad VaR model should incorporate a liquidity premium (or liquidity risk factor). This can be worked out by formulating a method by which one can unwind a position, not at some ad hoc rate, but at the rate that market conditions is optimal, so that one can effectively set a risk value for the liquidity effects. In general, this will raise significantly the $\mathrm{VaR}$, or the amount of economic capital $^{4}$ to support the trading position.

In fact, if returns are independent and they can have any elliptical multivariate distribution, then it is possible to convert the VaR horizon parameter from daily to any $t$-day horizon. The variance of a $t$-day return should be $t$ times the variance of a 1 -day return or $\sigma^{2}=f(t)$. Thus, in terms of standard deviation (or volatility), $\sigma=f(\sqrt{t})$ and the daily or overnight VaR number [VaR (1-day)] can be adjusted for any $t$-day horizon as:

$\operatorname{VaR}(t-d a y)=\operatorname{VaR}(1-d a y) \sqrt{t}$

The above formula was proposed and used by J.P. Morgan in their earlier RiskMetrics ${ }^{T M}$ method (1994). This methodology implicitly assumes that liquidation occurs in one block sale at the end of the holding period and that there is one holding period for all assets, regardless of their inherent trading liquidity structure and ultimately leads to an overstatement of VaR. Unfortunately, the latter approach does not consider real-life trading situations, where traders can liquidate (or rebalance) small portions of their trading portfolios on a daily basis. The assumption of a given holding period for orderly liquidation inevitably implies that assets' liquidation occurs during the holding period. Accordingly, scaling the holding period to account for orderly liquidation can be justified if one allows the assets to be liquidated throughout the holding period.

In this work we present a re-engineered approach for calculating a closed-form parametric L-VaR with explicit treatment of liquidity trading risk. The proposed model and liquidity scaling factor is more realistic and less conservative than the conventional root- $t$ multiplier. In essence the

\footnotetext{
${ }^{4}$ Economic capital can be defined as the minimum amount of equity capital a financial entity needs to set aside to absorb worst losses over a certain time horizon with a certain confidence level. This is with the objectives of sustaining its trading operations activities and without subjecting itself to solvency. Economic capital can be assessed with an internal method and modeling techniques such as L-VaR. Economic capital differs somehow from regulatory capital, which is necessary to comply with the requirements of Basel II committee on capital adequacy. However, building an internal market risk modeling techniques to assess economic capital can significantly aid the financial entity in complying with Basel II capital adequacy requirements.
} 
suggested multiplier is a function of a predetermined liquidity threshold defined as the maximum position which can be unwound without disturbing market prices during one trading day. The essence of the model relies on the assumption of a stochastic stationary process and some rules of thumb, which can be of crucial value for more accurate overall trading risk assessment during market stress periods when liquidity dries up. To this end, a practical framework of a methodology (within a simplified mathematical approach) is proposed below with the purpose of incorporating and calculating of illiquid assets' horizon L-VaR, detailed along these lines:

The market risk of an illiquid asset position is larger than the risk of an otherwise identical liquid position. This is because unwinding the illiquid position takes longer than unwinding the liquid position, and, as a result, the illiquid position is more exposed to the volatility of the market for a longer period of time. In this approach, a trading position will be well thought-out illiquid if its size surpasses a certain liquidity threshold. The threshold (which is determined by each trader) and defined as the maximum position which can be unwound, without disrupting market prices, in normal market conditions and during one trading day. Consequently, the size of the trading position relative to the threshold plays an important role in determining the number of days that are required to close the entire position. This effect can be translated into a liquidity increment (or an additional liquidity risk factor) that can be incorporated into $\mathrm{VaR}$ analysis. If for instance, the par value of a position is $\$ 10,000$ and the liquidity threshold is $\$ 5,000$, then it will take two days to sell out the entire trading position. Therefore, the initial position will be exposed to market variation for one day, and the rest of the position (that is $\$ 5,000$ ) is subject to market variation for an additional day. If it assumed that daily changes of market values follow a stationary stochastic process, the risk exposure due to illiquidity effects is given by the following illustration, detailed as follows:

In order to take into account the full illiquidity of trading assets (that is, the required unwinding period to liquidate an asset) we define the followings (Al Janabi, 2008):

$t=$ number of trading days for orderly liquidation of asset $i$ position

$\sigma_{a d j}^{2}=$ variance of the illiquid trading asset $i$; and

$\sigma_{a d j}=$ liquidity risk factor or standard deviation of the illiquid trading asset $i$.

The proposed approach assumes that the trading position is closed out linearly (liquidated in equal parts at the end of each day) over $t$-days and hence it uses the logical assumption that the losses due to illiquid trading positions over $t$-days are the sum of losses over the individual trading days. 
Moreover, we can assume with reasonable accuracy that asset returns and losses due to illiquid trading positions are independent and identically distributed (iid) and serially uncorrelated day-today along the liquidation horizon and that the variance of losses due to liquidity risk over $t$-days is the sum of the variance $\left(\sigma_{i}^{2}\right.$, for all $\left.i=1,2 \ldots, t\right)$ of losses on the individual days, thus:

$\sigma_{a d j}^{2}=\left(\sigma_{1}^{2}+\sigma_{2}^{2}+\sigma_{3}^{2}+\mathrm{L}+\sigma_{t-2}^{2}+\sigma_{t-1}^{2}+\sigma_{t}^{2}\right)=\sum_{i=1}^{t} \sigma_{i}^{2}$

In fact, the square root- $t$ approach (equation [5]) is a simplified special case of equation (6) under the assumption that the daily variances of losses throughout the holding period are all the same as first day variance $\left(\sigma_{1}^{2}\right)$, thus, $\sigma_{a d j}{ }^{2}=\left(\sigma_{1}{ }^{2}+\sigma_{1}{ }^{2}+\sigma_{1}{ }^{2}+\mathrm{L}+\sigma_{1}{ }^{2}\right)=t \sigma_{1}{ }^{2}$. As discussed earlier the square root- $t$ equation overestimates asset market/liquidity risk since it does not consider that traders can liquidate small portions of their trading portfolios on a daily basis and thus the whole asset trading position should be sold completely on the last trading day. However, this would be an overstatement of $\mathrm{VaR}$; and the true $\mathrm{VaR}$ has to be between the 1-day position $\mathrm{VaR}$ and 1-day position $\operatorname{VaR} \sqrt{t}$. Indeed, in real financial markets operations, liquidation occurs during the holding period and thus scaling the holding period to account for orderly liquidation can be justified if one allows the assets to be liquidated throughout the holding period. Certainly, for this special linear liquidation case and under the assumption that the variance of losses of the first trading day decreases linearly each day (as a function of $t$ ) we can derive from equation (6) the followings:

${\sigma_{a d j}}^{2}=\left(\left(\frac{t}{t}\right)^{2} \sigma_{1}{ }^{2}+\left(\frac{t-1}{t}\right)^{2} \sigma_{1}{ }^{2}+\left(\frac{t-2}{t}\right)^{2} \sigma_{1}{ }^{2}+\mathrm{L}+\left(\frac{3}{t}\right)^{2} \sigma_{1}{ }^{2}+\left(\frac{2}{t}\right)^{2} \sigma_{1}{ }^{2}+\left(\frac{1}{t}\right)^{2} \sigma_{1}{ }^{2}\right)$

In this manner, if the asset position is liquidated in equal parts at the end of each trading day, the trader faces a 1-day holding period on the entire position, a 2-day holding period on a fraction $(t$ $1) / t$ of the position, a 3-day holding period on a fraction $(t-2) / t$ of the position and so forth. Evidently, the additional liquidity risk factor depends only on the number of days needed to sell an illiquid trading position linearly. In the general case of $t$-days, the variance of the liquidity risk factor is given by the following mathematical functional expression of $t$ :

Copyright (C) Mazin A. M. Al Janabi, 2009-2010 
$\sigma_{a d j}^{2}=\sigma_{1}^{2}\left(\left(\frac{t}{t}\right)^{2}+\left(\frac{t-1}{t}\right)^{2}+\left(\frac{t-2}{t}\right)^{2}+\mathrm{L}+\left(\frac{3}{t}\right)^{2}+\left(\frac{2}{t}\right)^{2}+\left(\frac{1}{t}\right)^{2}\right)$

To calculate the sum of the squares, it is convenient to use a short-cut approach. From mathematical finite series the following relationship can be obtained:

$(t)^{2}+(t-1)^{2}+(t-2)^{2}+\mathrm{L}+(3)^{2}+(2)^{2}+(1)^{2}=\frac{t(t+1)(2 t+1)}{6}$

Hence, after substituting equation (9) into equation (8), the following can be achieved:

$\sigma_{a d j}^{2}=\sigma_{1}^{2}\left[\frac{1}{t^{2}}\left\{(t)^{2}+(t-1)^{2}+(t-2)^{2}+\mathrm{L}+(3)^{2}+(2)^{2}+(1)^{2}\right\}\right]$ or $\sigma_{a d j}{ }^{2}=\sigma_{1}^{2}\left(\frac{(2 t+1)(t+1)}{6 t}\right)$

Accordingly, from equation (10) the adverse price liquidity risk factor can be expressed in terms of volatility (or standard deviation) as:

$\sigma_{a d j}=\sigma_{1}\left\{\sqrt{\frac{1}{t^{2}}\left[(t)^{2}+(t-1)^{2}+(t-2)^{2}+\mathrm{L}+(3)^{2}+(2)^{2}+(1)^{2}\right]}\right\}$ or $\sigma_{a d j}=\sigma_{1}\left\{\sqrt{\frac{(2 t+1)(t+1)}{6 t}}\right\}$

The final result of equation (11) is of course a function of time and not the square-root of time as employed by some financial market's participants based on the RiskMetrics ${ }^{T M}$ methodologies. The above approach can also be used to calculate L-VaR for any time horizon. Likewise, in order to perform the calculation of L-VaR under illiquid market conditions, it is possible to use the adverse price liquidity factor of equation (11) and define the following single asset L-VaR:

$L-\operatorname{VaR}_{i_{a d j}}=\operatorname{VaR}_{i} \sqrt{\frac{\left(2 t_{i}+1\right)\left(t_{i}+1\right)}{6 t_{i}}}$

where $V a R_{i}=$ Value at Risk of asset $i$ under liquid market conditions; $L-V a R i_{a d j}=$ Value at Risk of asset $i$ under illiquid market conditions; and $t_{i}=$ number of trading days for orderly liquidation of the entire position of asset $i$ fully.

The latter equation indicates that $L-V a R i_{a d j}>V a R_{i}$, and for the special case when the number of days to liquidate the entire asset is one trading day, then $L-V a R i_{a d j}=V a R_{i}$. Consequently, the 
difference between $L-V a R i_{a d j}-V a R_{i}$ should be equal to the residual asset market risk due to the illiquidity of asset $i$ under illiquid markets conditions. As a matter of fact, the number of liquidation days or close out time $\left(t_{i}\right)$ necessary to liquidate the entire position of asset $i$ fully is related to the choice of the liquidity threshold; however the size of this threshold is likely to change under severe markets conditions. Indeed, the choice of the liquidation horizon can be estimated from the total trading position size and the daily trading volume that can be unwound into the market without significantly disrupting market prices; and in actual practices it is generally estimated as:

$t_{i}=$ Total Trading Position Size of Asset $/$ / Daily Trading Volume of Asset ${ }_{i}$

As such, the close out time $\left(t_{i}\right)$ is the time required to bring the positions to a state where the financial entity can make no further loss from the trading positions. It is the time taken to either sell the long positions or alternatively the time required to buy securities in case of short positions. In real practices the daily trading volume of any trading asset is estimated as the average volume over some period of time, generally a month of trading activities. In effect, the daily trading volume of assets can be regarded as the average daily volume or the volume that can be unwound under a severe crisis period. The trading volume in a crisis period can be roughly approximated as the average daily trading volume less a number of standard deviations. Albeit this alternative approach is quite simple, it is still relatively objective. Moreover, it is reasonably easy to gather the required data to perform the necessary liquidation scenarios.

In essence, the above liquidity scaling factor (or multiplier) is more realistic and less conservative than the conventional root- $t$ multiplier and can aid financial entities in allocating reasonable and liquidity market-driven regulatory and economic capital requirements. Furthermore, the above mathematical formulas can be applied for the calculation of L-VaR for every trading position and for the entire portfolio of assets. In order to calculate the L-VaR for the full trading portfolio under illiquid market conditions ( $\left.L-V_{a} R_{P_{a d j}}\right)$, the above mathematical formulation can be extended, with the aid of equation (3), into a matrix-algebra form to yield the following:

$$
L-\operatorname{VaR}_{P_{a d j}}=\sqrt{\left|L-V a R_{a d j}\right|^{T}|\rho|\left|L-V a R_{a d j}\right|}
$$


The above mathematical structure (in the form of two vectors, $\left|L-V a R_{a d j}\right|,\left|L-V a R_{a d j}\right|^{T}$, and a correlation matrix, $|\rho|$ ) can facilitate the mathematical modeling and programming process so that the trading risk manger can specify different liquidation horizons for the whole portfolio and/or for each individual trading asset according to the necessary number of days to liquidate the entire asset completely. The latter can be achieved by specifying an overall benchmark liquidation period to liquidate the entire constituents of the portfolio fully.

\subsection{Measure of Transactions Cost Market Liquidity Risk:}

Another additional alternative to quantify the asset liquidity risk is to measure the average bid-ask spread relative to the mid-price. The bid price is the utmost price that the market-maker is disposed to pay at a given time to purchase a particular amount of assets. Likewise, the ask price is the lowest price at which the market-maker is willing to sell a given amount of assets and the difference between the bid and ask prices (the bid-ask spread) reimburses the market-maker for the expediency of execution of orders offered to its counterparties. This spread measures the cost of a buy/sell or sell/buy cycle over a short period of time (that is, two-way transaction). For this reason, only half-spread should therefore be attributed to a single transaction (sale or purchase) if one considers that the mid-price is the one that should be paid in a perfect liquid market.

This traditional view of asset liquidity risk in trading portfolios is based on the fact that there is a relationship between price and quantity. Thus, when the quantity of an asset that is traded is relatively small, the bid-ask spreads are low and as the quantity increases, the price paid by the buyer of the asset increases and the price received by the seller of the asset decreases. That's why high liquid assets, such as major currencies or treasury bonds, are characterized by deep markets, where positions can be offset with very little price impact, while thin markets, such as over-the counter (OTC) derivative securities or some emerging markets equities, are those where any transaction can quickly affect prices.

Indeed, on one hand if the bid and ask prices are close to the mid-price then this implies that there are many market participants who consent on the fair price of the security and are disposed to trade close to that price. On the other hand, if the bid-ask spread is wide, this means that few investors are keen to buy the security at the price the sellers think is fair. Thus, if a trader sought to sell the security instantly, the trader would have to lower the ask price to equal the bid rather than pass the time waiting for some investor to assent that the high ask price was fair. To

\section{Copyright (C) Mazin A. M. Al Janabi, 2009-2010}


this end, the first and most easily measurable attribute is the quoted percentage bid-ask spread for an asset which can be defined formally as:

$\operatorname{Spread}_{i}\left(S_{i}\right)=\left[\right.$ ask price $_{i}-$ bid price $\left._{i}\right] /\left\{\left[\right.\right.$ ask price $_{i}+$ bid price $\left.\left._{i}\right] / 2\right\}$

However since $\left[\right.$ ask $_{\text {price }}+$ bid price $\left._{i}\right] / 2=$ mid-price $_{i}$, we can write equation (15) as:

$S_{i}=\left[\right.$ ask $_{\text {price }}-$ bid price $\left._{i}\right] /$ mid-price $_{i}$

Where the mid-price is halfway between the bid and the ask price and in liquidating a trading position the financial entity incurs a cost equal to $\left[A_{i} S_{i}\right] / 2$. Indeed, this reflects the fact that actual trades are not done at the mid-market prices, and a buy trade is done at a proportional amount $S_{i} / 2$ above the market price and a sell trade is done at a proportional amount $S_{i} / 2$ below the market price. Thus, it is possible to adjust for bid-ask spread by adding $\left[A_{i} S_{i}\right] / 2$ for each trading position in the portfolio. For a large trading portfolio with $n$-securities the total liquidity risk due to transaction cost can be defined formally as:

Transactions Cost Market Liquidity Risk $(T C M L R)=\sum_{i=1}^{n}\left\{A b s\left[A_{i}\right] S_{i}\right\} / 2$

Where 'Abs' indicates absolute value of $A_{i}$ since long and short trading positions have the same impact on widening the bid-ask spread and thus no netting effect should be induced on transactions cost. In fact, this adjustment with transaction cost can be repeated for all assets in the trading portfolio, leading to a series of add-ons, and this sequence of positive terms increases linearly with the number of assets.

Nevertheless, the quoted spread in financial markets is not usually a precise reflection of transaction costs (for a buy/sell cycle) as some deals may be traded not at the bid or the ask price but rather at prices sited within or even outside the spread, yet for typical amounts. Particularly, the spread is cited for restricted amounts and it ordinarily inclines to broaden in the existence of substantial order flows, which is what the notion of market depth refers to. Eventually, to realistically assess trading portfolios' risk exposure it is indispensable to contemplate the transaction costs incurred during the liquidation period.

A trouble-free method would consist in adding the observed average of the half-spread to the traditional VaR methods as other researchers have done heretofore. This method does not 
however comprise the variability of the half-spread over time. Given that the spread is a measure of the liquidity available at a given time, this is why it would be wiser to try to extract from historical data series information on the statistical distribution of bid-ask prices, and in particular on their volatility. With a view of an appropriate risk measurement, it is therefore important to encompass the bid-ask spread variability over time. Moreover, stress-testing and scenario analysis are also crucial to making the risk measures useful to financial institutions. Stress-testing will illustrate what the value of the trading portfolio will be in any given position. Furthermore, as volatility soars liquidity can dry out, hence, liquidity should also be stress-tested, as the bid-ask spread can reposition too by bounds and leaps in erratic markets. In what follows we present an improved model that takes into account the volatility of the spread and its variability over time till the last day of liquidating the whole trading position, detailed as follows:

We define transactions cost market liquidity risk measurement in terms of a confidence interval $(\alpha)$ or a tail probability. Moreover, we define transactions cost of market liquidity based on a certain average spread or an estimate of the expected or typical bid-ask spread, $\hat{S}_{i}$, plus a multiple of the spread volatility, $\sigma_{\mathrm{S}}$, to cover most of the spread situations. Thus, equation (17) can be expressed in terms of average spread and volatility of the spread as:

$T C M L R=\sum_{i=1}^{n}\left\{A b s\left[A_{i}\right] \times\left(\hat{S}_{i}+\alpha \sigma_{\mathrm{Si}}\right)\right\} / 2$

Under the zero-mean normality hypothesis, we can set $\hat{S}_{i}=S_{i}$, the most recent observation on the relative spread. For at least some financial assets such as hard currencies, it may be preferable to set $\hat{S}_{i}$ conformably to a well defined 'typical level'.

The above equation considers the average spread and its volatility but not the variability over time of the volatility factor; and hence an adjustment time factor is essential to reflect that volatility of spread is indeed also a function of time and it depends on the number of days left for full unwinding of the whole trading position. The essence of this assumption is based on the fact that the longer the number of days to liquidate fully the trading position there is a superior likelihood that the spread volatility is not static but rather dynamic and thus one would expect the spread to diverge even further and overlooked as time of liquidation elapses. In order to take this effect into consideration we proceed by defining that the trading position can be unwound in several days and for each trading day the remaining fraction(s) of the position will be the only

\section{Copyright (C) Mazin A. M. Al Janabi, 2009-2010}


remaining part(s) that can be influenced by the time-variability of the spread volatility, detailed along these lines:

In order to take into account the full illiquidity of assets (i.e. the required unwinding period to liquidate an asset and at which the bid-ask spread is likely to widen dynamically) we define the followings:

$h_{i}=$ the number of liquidation days, necessary to liquidate the entire position of asset $i$ fully, and that have direct influence on the movement in the bid-ask spread volatility.

$\sigma_{S i}^{2}=$ overnight (daily) variance of the bid-ask spread of asset $i$.

The proposed approach assumes that the trading position is closed out linearly (liquidated in equal parts at the end of each day) over $h_{i}$-days and hence it uses the logical assumption that the losses due to the widening of the bid-ask spread over $h_{i}$-days are the sum of losses over the individual trading days. Moreover, we can assume with reasonable accuracy that asset returns and losses due to the widening of the bid-ask spread are independent and identically distributed (iid) and serially uncorrelated day-to-day along the widening horizon and that the variance of losses due to bid-ask spread over $h_{i}$-days is the sum of the variance $\left(\sigma_{\operatorname{Sin}}{ }^{2}\right.$, for all $\left.n=1,2 \ldots, h_{i}\right)$ of the bid-ask spread losses on each individual day, thus:

$\sigma_{S i}^{2}=\left(\sigma_{S i_{1}}^{2}+\sigma_{S i_{2}}^{2}+\sigma_{S i_{3}}^{2}+\mathrm{L}+\sigma_{S i_{h}}^{2}\right)=\sum_{n=1}^{h_{i}} \sigma_{S i n}^{2}$

A linear liquidation procedure of the asset is assumed, that is, the trader can proceed by selling equal fractions of each asset every day till the last trading day $\left(h_{i}\right)$, where the entire asset is sold fully. Therefore, the remaining unsold fractions will be the only 'left-over' amounts of the trading asset that can be influenced, during the next trading day, by the time-varying volatility of the bidask spread. Indeed, for the special linear liquidation case and under the assumption that the current variance of losses of the bid-ask spread $\left(\sigma_{S i_{1}}{ }^{2}\right)$ increases linearly each day (as a function of $h$ ) hence, the following can be deduced:

$\sigma_{S i}{ }^{2}=\left(\left(\frac{1}{h_{i}}\right) \sigma_{S i_{1}}{ }^{2}+\left(\frac{2}{h_{i}}\right) \sigma_{S i_{1}}{ }^{2}+\left(\frac{3}{h_{i}}\right) \sigma_{S i_{1}}{ }^{2}+\mathrm{L}+\left(\frac{h_{i}}{h_{i}}\right) \sigma_{S i_{1}}{ }^{2}\right)$ 
In this manner, if the asset position is liquidated in equal parts at the end of each trading day, the trader faces a widening of the bid-ask spread on a 1-day holding period by $\left(1 / h_{i}\right)$ of the total position, a 2-day holding period on a fraction $\left(2 / h_{i}\right)$ of the position, a 3-day holding period on a fraction $\left(3 / h_{i}\right)$ of the position and so forth. Evidently, the additional transactions cost liquidity risk factor depends only on the number of days needed to sell an illiquid trading position linearly. In the general case of $h_{i}$-days, the variance of the widening of bid-ask spread is given by the following mathematical functional expression of $h_{i}$ :

$\sigma_{S i}{ }^{2}=\sigma_{S i_{i}}{ }^{2}\left(\left(\frac{1}{h_{i}}\right)+\left(\frac{2}{h_{i}}\right)+\left(\frac{3}{h_{i}}\right)+\mathrm{L}+\left(\frac{h_{i}}{h_{i}}\right)\right)$ or $\sigma_{S i}{ }^{2}=\sigma_{S i_{1}}{ }^{2}\left(\frac{1}{h_{i}}\left(1+2+3+\ldots \ldots . .+h_{i}\right)\right)$

To calculate the sum of the time fractions of the liquidation horizon, it is convenient to use a shortcut approach. From mathematical finite series the following relationship can be obtained:

$$
\left(1+2+3+\ldots \ldots+h_{i}\right)=\frac{h_{i}\left(h_{i}+1\right)}{2}
$$

Accordingly, equation (21) can be simplified to:

$\sigma_{S i}^{2}=\sigma_{S i_{1}}^{2}\left[\frac{1}{h_{i}}\left(1+2+3+\ldots \ldots . .+h_{i}\right)\right]$ or $\sigma_{S i}^{2}=\sigma_{S i_{1}}^{2}\left(\frac{h_{i}+1}{2}\right)$

Consequently, the volatility of the bid-ask spread as a function of bid-ask spread widening period $h_{i}$ is:

$\sigma_{S i}=\sigma_{S i_{1}}\left\{\sqrt{\frac{1}{h_{i}}\left(1+2+3+\ldots \ldots+h_{i}\right)}\right\}$ or $\sigma_{S i}=\sigma_{S i_{1}}\left\{\sqrt{\frac{h_{i}+1}{2}}\right\}$

Substituting equation (24) into equation (18) yields the following time-varying bid-ask spread volatility relationship:

TCMLR $=\sum_{\mathrm{i}=1}^{\mathrm{n}}\left\{A b s\left[A_{i}\right] \times\left(\hat{S}_{\mathrm{i}}+\alpha \sigma_{S i_{1}} \sqrt{\frac{h_{i}+1}{2}}\right)\right\} / 2$

Copyright (C) Mazin A. M. Al Janabi, 2009-2010 
We will refer to the above equation as the percentile dynamic spread risk factor. Obviously, the dynamic spread risk factor is a function of time and reflects the stochastic nature of the bid-ask spread. Like so, the transactions cost market liquidity risk at a $\alpha$ confidence level is then measured by the current value of the spread risk factor, or by the $\alpha$ percentile of the actual proportional daily changes in the half-spread over a given historical period, adjusted by a time function that denotes the necessary time to liquidate the asset fully. For all practical purposes it is possible to assume that the bid-ask spread widening period $\left(h_{i}\right)$ and the asset unwinding period $\left(t_{i}\right)$ are equivalent, that is, $h_{i}=t_{i}$. Although this assumption may sound rather strong, in reality both $h_{i}$ and $t_{i}$ time periods are interrelated most of the time and can be considered equivalent for the sake of facilitating the programming process of both asset market/liquidity risk models.

\subsection{Assessing Overall Asset Market and Liquidity Risks:}

Trading returns are typically measured from mid-market prices. Although this may be adequate for measuring daily profit and loss $(P \& L)$, it may not represent the actual fall in value if a large portfolio is to be liquidated. More specifically, the VaR method uses the mid-price or last price, ignoring the fact that liquidation occurs not at the bid-ask average price, but at the bid-ask average less half the bid-ask spread and this spread can fluctuate widely. Marking to market leads to an underestimation of the true risks because the realized value upon liquidation can deviate significantly from the market mid-price. Given the bid/offer spread that exists in the marketplace, and given that the bid/offer spread varies with how much one can unwind a trading position, the actual risk depends on the overall trading position size relative to the size that can be unwind. As discussed above, though $\mathrm{VaR}$ method in recent years has become a reference for market risk management the model does not satisfactorily capture asset liquidity risk, which is an integral component of market risk and thus should not be treated or assessed in an isolated framework. The question that may arise is how to assess potential market/liquidity risk loss aggregates jointly under such conditions, which in turn can give insights into how to manage this risk.

Previous attempts were fulfilled by using standard VaR calculations and adjusting the result to the distribution of bid-ask spreads with the aim of calculating the most unfavorable halfspread for a given time horizon and confidence threshold. The highest bid-ask spread liquidity cost is thus obtained and then added to the standard $\mathrm{VaR}$ defined for the same time horizon and the same confidence interval. Indeed, assessing the overall market/liquidity risk of an asset by simply summing up its price risk cost (which is reflected by traditional VaR model) and the bid-ask spread

\section{Copyright (C) Mazin A. M. Al Janabi, 2009-2010}


liquidity cost amounts to deducing that these two asset market/liquidity components are absolutely correlated (that is, the high variability of the mid-price is associated with the high variability of the bid-ask spread). This presumption may on several occasion causes an underestimation of the overall market risk.

To this end, in this paper we conceptually aspire not to split the uncertainty in market value of an asset, i.e. its overall market risk, into two parts: uncertainty that arises from asset returns, which can be thought of wrongly as a pure market risk component, and uncertainty due to liquidity risk component, as others researchers have done beforehand. In this way, we argue that market and liquidity risk components are correlated in most cases and can be integrated into one single market/liquidity value that consists of two interconnected sub-components. The first component of asset market/liquidity risk is attributed to the unwinding period or to the impact of adverse price movements. In contrast, the second component of market/liquidity risk measures focuses on the risk of variation in transactions costs due to bid-ask spreads and it attempts to measure the likelihood that it will cost more than expected to liquidate the position and can be assessed as a percentile dynamic spread risk factor.

Certainly, both components play an important role in defining and quantifying asset market/liquidity risk and these starting points allow us to define the overall asset market and liquidity risks as the sum of both components bearing in mind that in real world financial operations it is not feasible to distinguish clearly between market and liquidity risks and hence an assessment yardstick can be devised to appraise both market and liquidity risk simultaneously as one integrated component. Indeed, the first attribute already includes the impact of market risk and diversification benefits and can produce purely market risk exposure when the liquidation horizon (or unwinding period) is resets for one trading day. The second attribute can diminish in importance if the market is able to absorb order flows without provoking violent price adjustment that are unrelated to fundamental value. Since market and liquidity risk components are correlated in most cases, we can argue that:

Overall Asset Market Liquidity Risks $(O A M L R)=$ Adverse Price Impact Market/Liquidity Risk + Transactions Cost Market/Liquidity Risk 
Equation (14) represents the total adverse price impact market/liquidity risk on a portfolio level $\left(L-V a R_{P_{a d j}}\right)$ while equation (25) characterizes the aggregate transaction cost market/liquidity risk for all trading assets, so that:

$$
O A M L R=\sqrt{\left|L-V a R_{a d j}\right|^{T}|\rho|\left|L-V a R_{a d j}\right|}+\sum_{\mathrm{i}=1}^{\mathrm{n}}\left\{A b s\left[A_{i}\right] \times\left(S_{\mathrm{i}}+\alpha \sigma_{S i_{1}} \sqrt{\frac{h_{i}+1}{2}}\right)\right\} / 2
$$

As the number of long positive positions, $n$, increases, the first term $L-V a R_{P_{a d j}}$ benefit from diversification effects but the second transactions cost term does not. Thus, the relative importance of the second liquidity factor will be greater for large portfolios regardless if it is long or short trading positions. Indeed, ignoring any of the two components of market liquidity effect can produce underestimates of the overall market risk, particularly in emerging markets. Accordingly, the Basel II Capital Accord by not modeling asset market/liquidity risk unambiguously as part of the overall market/liquidity uncertainty and therefore capitalizing against it, financial entities will be encountering many violations of their capital requirements, particularly if their trading portfolios are located in emerging markets.

Admittedly, under ordinary situations, asset liquidity risk can be expected to be a diminutive part of financial-intermediaries' total market risk, and that as a minimum certain aspects of it can be at least approximately assessed by some of the statistical measures described here. However, at times of financial tension, asset liquidity risk can become a far more important part of the overall market risk. Precisely at these upheaval times, standard asset market liquidity risk measures are likely to be entirely deceptive. Assessing and monitoring asset market/liquidity risk should therefore be considered as an integral part of preparing for stress-testing and warning signals analysis. As such, asset market/liquidity risk should be treated as an essential part of managing the risk of extreme events, as during periods of market stress, time is of essence. Thus, early warning signals can be used by market participants to assess stress-tests, categorize vulnerabilities, and devise earlier liquidation and hedging of exposures decisions.

\section{SUMMARY AND DISCUSSION}

The last few years have witnessed a rapid expansion of emerging markets financial assets trading activities - with several turmoil in capital markets - and an increasing interest in the measurement and management of asset liquidity risk for portfolio management and asset allocation purposes. It 
is thus essential, at this stage, to be able to adapt the definition of traditional tools of quantifying trading risk to the needs and the requirements of this new environment in which the asset liquidity factor plays a central role. Asset liquidity is a key factor in formalizing and measuring overall trading risk and neglecting liquidity risk can lead to underestimation of overall trading risk and to undercapitalization of financial institutions, particularly if their portfolios are concentrated in emerging markets. This has assumed special significance as more and more financial entities, particularly in emerging markets, prepare themselves towards better internal modeling of trading risk within the context of Basel II Capital Accord guidelines.

Despite this, no standard technique for evaluating asset market/liquidity risk has surfaced. Definitely, Liquidity-Adjusted VaR (L-VaR) models do exist and during the last decade, L-VaR became one of the most popular tools for assessing trading risk across financial institutions. In fact, some L-VaR models are relatively sophisticated, however most of these models are related to single security VaR approaches and their application to trading portfolios is inconsistent. Other unsophisticated methods such as those that rely on mainstream measures of leverage to appraise asset liquidity risk provide now and then worthless results.

In fact, classical $\mathrm{VaR}$ calculation is about the cost of liquidating traded portfolios in an adverse market, and provides an estimate of the maximum potential loss that may be incurred on a position at a given time horizon and level of confidence, however it does not separate market risk from liquidity risk. Although in recent years it has become a reference for market risk management, the VaR model does not satisfactorily capture asset liquidity risk, which is a fundamental component of market risk. In calculating $\mathrm{VaR}$, it is generally assumed that the trading position can be liquidated or hedged within a fixed and reasonably short timeframe. Moreover, it is assumed that the liquidation of assets positions have no effect on market prices and that the bid-ask spread remains stable irrespective of the size of the position. Indeed, traditional VaR methods take for granted perfect markets, where an investor can buy and sell any amount of financial securities without causing a significant price change. Such a hypothesis is rarely confirmed in real financial market practices, particularly in emerging markets environments, and as a result could lead to an underestimation of conventional $\mathrm{VaR}$ risk measures.

Additionally, the VaR method uses the mid-price or last known market price, ignoring the fact that liquidation occurs not at the bid-ask average price, but at the bid-ask average less half the bid-ask spread and this spread can fluctuate widely. However, as we have seen earlier, the quoted market price should not be used as a basis for reevaluating a portfolio that is to be sold on a less

\section{Copyright (C) Mazin A. M. Al Janabi, 2009-2010}


than perfectly liquid market and in practical terms an account must be taken of its orderly liquidation value and the variation of its bid-ask spread throughout the liquidation period. In conclusion, the standard $\mathrm{VaR}$ model is unreliable guide because it ignores the risk to which a portfolio is exposed during its liquidation period. It is nonetheless doable to adapt VaR measures so as to integrate trading execution costs into the risk assessment framework. There are certainly ad hoc techniques for reevaluating VaR by artificially escalating the volatility of positions deemed illiquid, or by enlarging the time horizon employed for calculating VaR. However, because they advocate subjective adjustments, these techniques do not deal straightforwardly with the issue of asset market/liquidity risk.

Given the rising need for measuring, managing and controlling of financial risk, trading risk prediction under liquid and illiquid market conditions plays an increasing role in banking and finance sectors. To this end, this paper focuses on contemporary practice and proposes a new internal model for calculating asset market liquidity and within a multivariate context. In reality, one of the main challenges in the VaR concept is that the risk of a portfolio is measured independently from its size which is equivalent to assuming constant market liquidity regardless of portfolio size. Indeed, this effect can be included in VaR assessments by adjusting the holding period to take size into account not at an ad hoc liquidity multiplier but rather with a liquidity risk factor that reflects real-world trading practices. That's why, a range of low liquidity premium securities has to be identified and then for each class a quantification of the smallest and the largest amount of securities that can be unwound need to be performed. When a position becomes too small or too large, a holding period of longer than one day must be applied. To this end, an attempt is made to remedy the above shortcomings by defining market and liquidity risks jointly as the sum of two interrelated components. In view of that, this paper looks at the dual and related dilemmas of:

1. Adjusting traditional VaR method at a portfolio level to reflect adverse price movements, during the unwinding period $\left(t_{i}\right)$, on the liquidation of trading asset and without invoking the root- $t$ rule.

2. Incorporation of a time-varying transactions cost into the overall assessment of asset market/liquidity risk during the bid-ask spread widening period $\left(h_{i}\right)$.

Under this framework, the liquidation risk of a trading position will not only include the bid/ask spread as other researchers have done heretofore, but in addition a realistic liquidity risk factor that

\section{Copyright (C) Mazin A. M. Al Janabi, 2009-2010}


takes into consideration meaningful operational and financial circumstances. This mutual characterization of market and liquidity risks provides a simple and convenient modeling technique for including asset market/liquidity risk into VaR computations which is now standard in risk management procedures. Undeniably, the asset/market liquidity framework presented in this paper does not incorporate all the aspects of liquidity trading risk. However, it is effective as a tool for evaluating trading risk when the impact of illiquidity of specified financial products is significant.

The following step in this research is to select a particular emerging market or a region and strive to apply the proposed model to a specific trading portfolios and then to assess empirically the impact of market and liquidity risks on the overall trading risk exposure. We aspire in a second empirical research paper to apply the developed theoretical modeling approach to the particular case of an emerging market trading portfolio and analyze the impact of both adverse price impact and transactions cost on the overall market/liquidity risk profiles.

\section{REFERENCES}

1. Al Janabi, M. A.M. (2008), "Integrating Liquidity Risk Factor into a Parametric Value at Risk Method", Journal of Trading, summer issue, pp. 76-87.

2. Al Janabi, M. A. M. (2007), "On the Use of Value At Risk for Managing Foreign Exchange Exposure in Large Portfolios”, Journal of Risk Finance, Vol. 8, No. 3, pp. 260287, 2007.

3. Al Janabi, M. A. M. (2005), "Trading Risk Management: Practical Applications to Emerging-Markets," in Motamen-Samadian S. (Ed.), Risk Management in Emerging Markets, Palgrave/MacMillan, UK, pp.91-136.

4. Almgren, R. and Chriss, N. (1999), "Optimal Execution of Portfolio Transaction," Working Paper, Department of Mathematics, The University of Chicago.

5. Angelidis, T. and Benos, A. (2006), "Liquidity adjusted Value-at-Risk Based on the Components of the Bid-Ask Spread," Applied Financial Economics, Vol. 16, No. 11, pp. 835-851.

6. Bangia, A., Diebold, F., Schuermann, T. and Stroughair, J. (1999), "Modeling Liquidity Risk with Implications for Traditional Market Risk Measurement and Management," Working Paper, The Wharton School, University of Pennsylvania.

7. Berkowitz, J. (2000), "Incorporating Liquidity Risk into VAR Models," Working Paper, Graduate School of Management, University of California, Irvine. 
8. Danielsson, J., and Zigrand, J-P. (2006), "On time-scaling of risk and the squareroot-of-time rule," Journal of Banking \& Finance, Vol. 30, No. 10, pp. 2701-2713.

9. Dowd, K., Blake, D., and Cairns, A. (2004), "Long-Term Value at Risk," The Journal of Risk Finance, Winter/Spring Issue, pp. 52-57.

10. Hisata, Y. and Yamai, Y. (2000), "Research Toward the Practical Application of Liquidity Risk Evaluation Methods," Discussion Paper, Institute for Monetary and Economic Studies, Bank of Japan.

11. Jarrow, R. and Subramanian, A. (1997), "Mopping up Liquidity," Risk, Vol. 10, No. 12, pp. 170-173.

12. Le Saout, E. (2002), "Incorporating Liquidity Risk in VaR Models," Working Paper, Paris 1 University.

13. Madhavan, A., Richardson, M. and Roomans, M. (1997), "Why do security prices change? A transaction-level analysis of NYSE stocks," Review of Financial Studies, Vol. 10, pp. 1035-1064.

14. Morgan Guaranty Trust Company (1994), "RiskMetrics-Technical Document," New York: Morgan Guaranty Trust Company, Global Research.

15. Roy, S. (2004), "Liquidity Adjustment in VaR Model: Evidence from the Indian Debt Market, Reserve Bank of India Occasional Papers, Vol. 25, No. 1-3, pp.1-16.

16. Shamroukh, N. (2000), "Modeling Liquidity Risk in VaR Models," Working Paper, Algorithmics UK.

Copyright (C) Mazin A. M. Al Janabi, 2009-2010 